\title{
Trypanosoma cruzi (kinetoplastida, Trypanosomatidae) genotypes in neotropical bats in Brazil
}

\author{
Cristiane Varella Lisboa ${ }^{a}$, Ana Paula Pinho ${ }^{\text {a }}$, Heitor Miraglia Herrera ${ }^{a}$, \\ Marconny Gerhardt ${ }^{\mathrm{c}}$, Elisa Cupolillo ${ }^{\mathrm{d}}$, Ana Maria Jansen ${ }^{\mathrm{a}, *}$ \\ ${ }^{a}$ Laboratório de Biologia de Tripanosomatídeos, Instituto Oswaldo Cruz, FIOCRUZ, Av. Brasil 4365, \\ 21040-900 Rio de Janeiro, Brazil \\ ${ }^{\mathrm{b}}$ EMBRAPA/Pantanal, Rua 21 de Setembro, 1880, 79320-900 Corumbá, Brazil \\ ${ }^{\mathrm{c}}$ Laboratório de Biologia e Parasitologia de Mamíferos Silvestres Reservatórios, Instituto Oswaldo Cruz, FIOCRUZ, \\ Av. Brasil 4365, 21040-900 Rio de Janeiro, Brazil \\ ${ }^{\mathrm{d}}$ Laboratório de Pesquisa em Leishmanioses, Instituto Oswaldo Cruz, FIOCRUZ, Av. Brasil 4365, \\ 21040-900 Rio de Janeiro, Brazil
}

Received 9 April 2008; received in revised form 9 June 2008; accepted 9 June 2008

\begin{abstract}
Few studies have been conducted to investigate the role played by the order Chiroptera in the sylvatic transmission cycle of Trypanosoma cruzi or their putative association with the main genotypes of the parasite. Here, the purpose was to enlarge the knowledge of this issue, in this sense, 93 specimens of bats included in 4 families, respectively Molossidae, Noctilionidae, Phyllostomidae and Vespertilionidae collected in distinct regions of Brazil were submitted to fresh blood smears and hemocultures. No patent parasitemia was observed but positive hemocultures by T. cruzi were observed in 14\% (13/93) of examined samples. The majority of the parasite isolates were obtained from Phyllostomus hastatus (80\%) captured in one same buriti hollow palm tree in the Cerrado region. Multilocus enzyme electrophoresis (MLEE) analyses showed that the genetic distance among these isolates was 0.35 , almost the same observed when all the isolates (excluding the reference strains) were analyzed (0.40). No correlation of zymodeme with bat genera, species or geographic region of its origin could be observed, moreover, correlation of zymodeme and genotype of the parasite was not strict. Ten out of $14 T$. cruzi isolates obtained from bats corresponded to the TCII genotype. Chiropterans with TCI, TCII/TCIII mixed infection as well as Trypanosoma rangeli in single or mixed infections were observed. These results show that bats may harbor and are probably important maintainers of the main genotypes (TCI, TCII, TCIII/Z3) of $T$. cruzi. These results support the absence of an association of TCII with any mammal order and show that bats, mainly P. hastatus, may act as amplifier hosts of TCII subpopulations of T. cruzi.
\end{abstract}

(C) 2008 Elsevier B.V. All rights reserved.

Keywords: Trypanosoma cruzi; TCI; TCII; TCIII/Z3 genotype; Neotropical bats

\section{Introduction}

Trypanosoma cruzi, agent of Chagas' disease, a predominantly clonal taxon, displays a meaningful genetic and phenotypic diversity (Tibayrenc and Ayala,

\footnotetext{
* Corresponding author. Tel.: +55 212598 4324; fax: +552125606572 .

E-mail address: jansen@ioc.fiocruz.br (A.M. Jansen).
} 1999). Two main genotypes were recognized as including the huge amount of the subpopulations of this heterogeneous trypanosomatid, respectively, T. cruzi I 
(TCI) and T. cruzi II (TCII) (Satellite Meeting, 1999). More recently a new group, TCIII, correspondent to zymodeme Z3 of Miles et al. (1980) with hybrid events, was described (De Freitas et al., 2006). In these genotypes, mainly in TCII, several subtypes are currently recognized (Rozas et al., 2007). T. cruzi I is supposed to be associated with the sylvatic transmission cycle and mainly to marsupials while TCII was considered associated, in Brazil, to human cases of Chagas disease in domestic transmission cycles. More recent studies concerning the ecology of $T$. cruzi in natural environments have shown the presence of TCII also in sylvatic transmission cycles circulating at least in five orders of mammals: Primates, Rodentia, Marsupialia, Xenarthra and Carnivora (Lisboa et al., 2006). Concerning TCI, human infection and disease by this genotype has been observed in the Amazon region (Coura et al., 2002). Consequently, the putative association of genotypes TCI and TCII with the transmission cycle or mammalian host is still an open question; in fact both genotypes can occur in overlapping or in distinct and independent transmission cycles in the wild, the domicile or peridomicile (Jansen et al., 1999).

Chiroptera, a very abundant and ancient mammalian group, has an ancient co-evolutive history with tripanosomatids (Molyneux and Stiles, 1991; Stevens et al., 1999). Despite its abundance and broad dispersion in nature, few studies have been conducted, mainly concerning the occurrence of the main genotypes of T. cruzi in bats. Here, the main purposes were to study the prevalence of $T$. cruzi infection in bat species from different ecosystems in Brazil and to verify the occurrence of the main genotypes of $T$. cruzi (TCI, TCII and TCIII/Z3) in these bats.

\section{Material and methods}

\subsection{Origin of the studied bats}

Ninety-three bats representing 16 species from 14 genera were sampled in distinct geographic biomes: the Amazon Forest (Itupiranga and Cachoeira do Arari, PA), the Atlantic Rainforest (Poço das Antas Biological Reserve, Silva Jardim, RJ), the Caatinga (Coronel José Dias, PI), the Cerrado (Luziania and Aporé, GO) and the Pantanal (Southeast Pantanal, MS) between 1996 and 2006.

\subsection{Field procedure}

The bats were non-injuriously captured with a special net and anesthetized with $20 \mathrm{mg} / \mathrm{kg}$ body weight ketamine (Ketalar ${ }^{\circledR}$-Parke-Davis, New Jersey, USA) for blood collection. Approximately $0.3 \mathrm{ml}$ of whole blood obtained by cardiac puncture was placed on NNN medium (Novy, McNeal and Nicolle), covered with an overlay of LIT (Liver Infusion Tryptose) containing $10 \%$ fetal calf serum and $140 \mu \mathrm{g} / \mathrm{ml}$ of gentamycin sulfate. Two blood smears from each animal were Giemsa-stained and examined for patent parasitemia.

\subsection{Trypanosoma isolates}

Two tubes of hemocultures from each bat were examined twice monthly up to 5 months. Parasites from positive hemocultures were amplified in LIT until the exponential phase was centrifuged $(1400 \times g)$ and the cell pellet resuspended in $0.2 \mathrm{ml}$ of TE buffer $(10 \mathrm{mM}$ Tris-HCl, $\mathrm{pH}$ 8.0, $10 \mathrm{mM}$ EDTA) $\mathrm{pH} 8.0$ for cryopreservation and posterior biochemical and molecular characterization.

\subsection{Biochemical characterization}

Twelve T. cruzi isolates derived from bats species were analyzed by multilocus enzyme electrophoresis (MLEE) that was carried out on agarose gels following procedures previously described (Cupolillo et al., 1994). Nine enzymatic systems were studied: glucosephosphate dehydrogenase (G6PDH, E.C. 1.1.1.49), glucose-phosphate isomerase (GPI, E.C. 5.3.1.9.), malic enzyme (ME, E.C. 1.1.1.40), isocitrate dehydrogenase (IDH, E.C. 1.1.1.42), malate dehydrogenase (MDH, E.C. 1.1.1.37), peptidases (PEP1, E.C. 3.4.11; PEP2, E.C. 3.4.11.1), 6-phosphogluconate dehydrogenase (6PGDH, E.C. 1.1.1.43) and phosphoglucomutase (E.C. 2.7.51). Two reference strains were used in each electrophoretic procedure: M1 (MDID/Br/99/M1/T. cruzi I/TCI) and M2 (MDID/Br/99/M1/T. cruzi II/TCII). Genetic differences among isolates were estimated by Jaccard's index $(D)$ and a dendrogram was constructed using the unweighted pair-group method with arithmetic averages (UPGMA). A bootstrap analysis was performed using 1000 replicates. All numerical analysis were conducted using the software "Free Tree" (Pavlícek et al., 1999).

\subsection{Molecular characterization}

The genomic DNA of the lysed cells was extracted with phenol:chloroform $(1: 1)$ and precipitated after the addition of sodium acetate and ethanol (Sambrook et al., 1989). Differential amplification of part of the nontranscribed spacer of the mini-exon gene could be 
achieved using a pool of five oligonucleotides for the PCR. The oligonucleotides and PCR conditions used in this study were described elsewhere (Fernandes et al., 2001). The amplification products were analyzed by $2 \%$ agarose gel electrophoresis, followed by ethidium bromide staining and UV visualization. Four isolates were used as controls TCI (200 bp), TCII (250 bp), TCIII/Z3 (150 bp) and Trypanosoma rangeli (100 bp).

\section{Results and discussion}

Bats of the family Phyllostomidae represented 92\% of the sampled chiropterans; moreover T. cruzi infection was detected in bats of all surveyed biomes. T. cruzi infection was demonstrated only by hemocultures since no patent parasitemia was observed in fresh blood smears. T. cruzi positive hemocultures were obtained from $14 \%$ (13/93) of the examined bats. In addition, the distribution of infection by $T$. cruzi in bats displayed an aggregate character given that the majority of positive hemocultures of T. cruzi were obtained in Phyllostomus hastatus (7/10) that were captured in one single tree hollow, a buriti palm tree localized in Aporé (Cerrado). The other $T$. cruzi isolates were obtained from $P$. hastatus, Artibeus cf. fimbriatus and Epitesicus sp. captured in the Amazon forest and P. hastatus and Artibeus jamaicensis captured in the Pantanal.

Phyllostomidae is the most prevalent bat family in the Brazilian territory, representing $57 \%$ of extant bats and, considering their expressive biomass and dispersion, the present data show that this taxon plays an important role in the maintenance and dispersion of T. cruzi. Hematophagic habits do not seem to be important in the transmission of $T$. cruzi among bats

\section{Isolates Zymodemes}

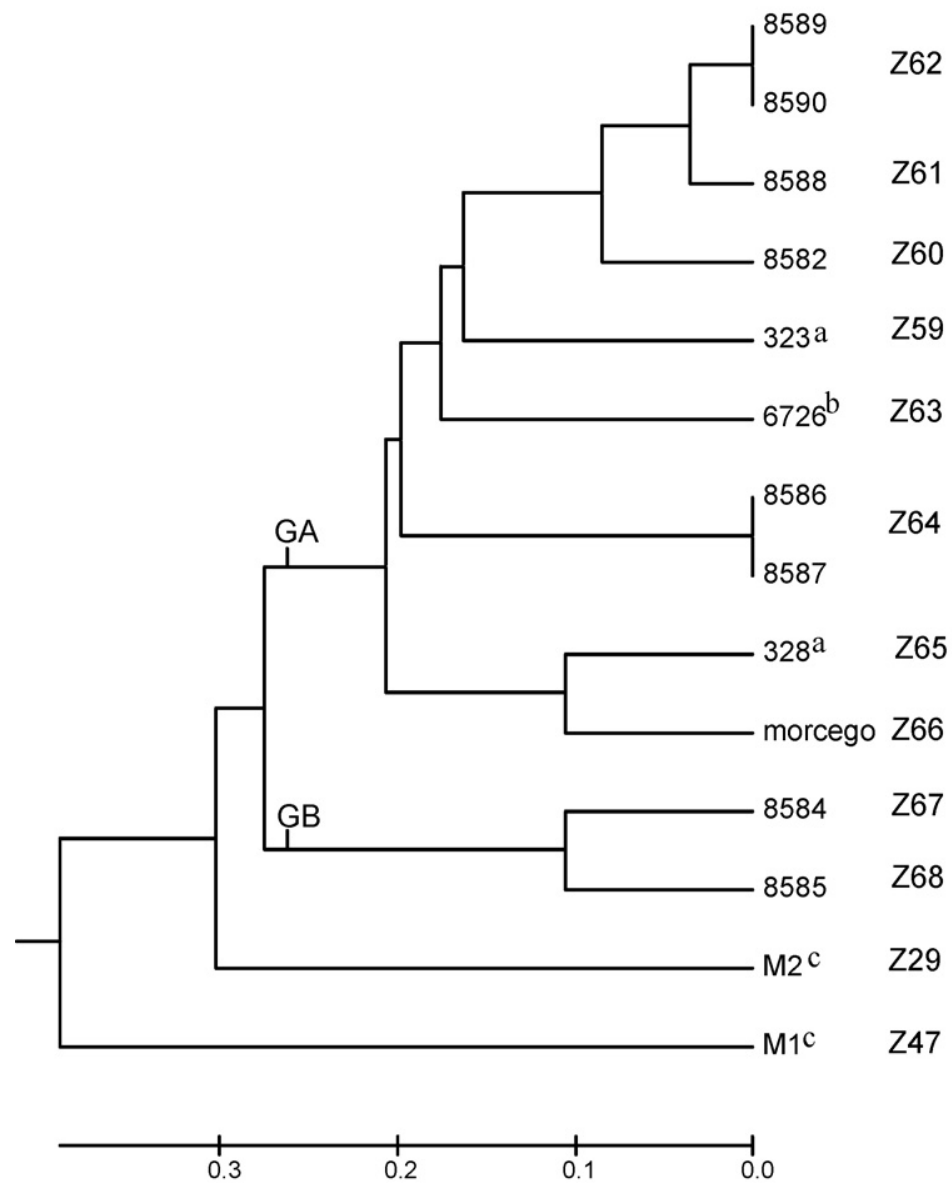

Fig. 1. MLEE phenogram of 12 isolates derived from bats showing the genetic distance among Trypanosoma cruzi zymodemes. Letter a corresponds to isolates of $T$. cruzi typed as TCII/Z3 (mixed infection), letter b corresponds to isolate of $T$. cruzi typed as TCI and letter c corresponds to reference strains $(\mathrm{M} 1=\mathrm{TCI}$ and M2 $=\mathrm{TCII})$. GA and GB correspond to the two separated branches. 
since none of the 23 examined Desmodus rotundus was observed infected with T. cruzi; probably due to the fact that Desmodus feeds preferentially on livestock, which are not considered reservoirs of $T$. cruzi. In contrast, Artibeus (family Phyllostomidae) and Epitesicus (family Vespertilionidae), that feed on plant sources, consuming significant quantities of insects, were shown to have been exposed to $T$. cruzi infection. It is important to consider that Artibeus is associated with Acromia palm trees, which are known to be the habitat of small wild mammals and great numbers of triatomine vectors (Zortea, 2003). Probably these bats genera acquire the infection by $T$. cruzi through transmission by the oral route since these species also consume a huge quantity of insects.

T. cruzi isolates derived from bats clustered into two well separated branches (A and B) (Fig. 1). The group GA clustered most of the zymodemes (10 isolates/8 zymodemes). All isolates in this group were characterized as TCII genotype (two bats with mixed TCII/Z3 infection) except for one isolate which was characterized as TCI (Fig. 1). The other group, GB, included only two isolates, belonging to distinct zymodemes with low genetic distance $(D=0.21)$ and both were characterized as TCII. The genetic distances in the cluster grouping the isolates from bats ranged from 0.08 to 0.73 with an overall average of 0.40 . No correlation of zymodeme with bat genera, species or geographic region of its origin could be observed, moreover, correlation of zymodeme and genotype of the parasite was not strict. Analyses of the genetic distances among $T$. cruzi isolates derived from P. hastatus captured in the same hollow of tree showed an average of 0.35 , almost the same observed when all the isolates (excluding the reference strains) were analyzed (0.40).

Particularly interesting is the heterogeneity observed in the T. cruzi isolates derived from the bats of the same hollow tree. This aspect probably reflects that these bats acquired the infection from different infection sources during time spend hunting. Phyllostomidae display recognizably eclectic feeding habits and are avid insects feeders; moreover, the oral route is a common and effective mechanism for wild mammals acquiring $T$. cruzi infection (Willig et al., 1993).

The analysis based on a variable spot of the nontranscribed spacer of the mini-exon gene of T. cruzi independent of localities demonstrated that bats are able to harbor the three genotypes (TCI, TCII and TCIII/Z3) as well as mixed infections (Table 1).

Bat infection with TCI in Pará (AM) was expected since hitherto this genotype had been described most often in this northern region of Brazil. However, this
Table 1

Molecular characterization of 14 isolates of Trypanosoma cruzi derived from sylvatic Neotropical bats from different biomes in Brazil

\begin{tabular}{|c|c|c|c|}
\hline Biome & Locality & Species $^{\mathrm{a}}$ & Genotype \\
\hline \multirow[t]{3}{*}{ Amazon } & Itupiranga & $\begin{array}{l}\text { Phyllostomus } \\
\text { hastatus }\end{array}$ & TCI \\
\hline & \multirow[t]{2}{*}{$\begin{array}{l}\text { Cachoeira } \\
\text { do Arari }\end{array}$} & $\begin{array}{l}\text { Artibeus cf. } \\
\text { fimbriatus }\end{array}$ & TCI \\
\hline & & Epitesicus sp. & TCI \\
\hline \multirow[t]{8}{*}{ Cerrado } & \multirow[t]{8}{*}{ Aporé } & P. hastatus & $\mathrm{TR}^{\mathrm{b}}$ \\
\hline & & P. hastatus & $\mathrm{TCII} / \mathrm{TR}^{\mathrm{c}}$ \\
\hline & & P. hastatus & TCII \\
\hline & & P. hastatus & TCII \\
\hline & & P. hastatus & TCII \\
\hline & & P. hastatus & TCII \\
\hline & & P. hastatus & TCII \\
\hline & & P. hastatus & TCII \\
\hline \multirow[t]{3}{*}{ Pantanal } & \multirow[t]{3}{*}{ Nhecolândia } & P. hastatus & TCII \\
\hline & & P. hastatus & $\mathrm{TCII} \mathrm{TCIII}^{\mathrm{d}}$ \\
\hline & & $\begin{array}{l}\text { Artibeus } \\
\text { jamaicensis }\end{array}$ & $\mathrm{TCII} / \mathrm{TCIII}^{\mathrm{d}}$ \\
\hline
\end{tabular}

Total $14 / 93^{\mathrm{e}}$

\footnotetext{
${ }^{\mathrm{a}}$ Family Phyllostomidae.

b TR: Trypanosoma rangeli.

${ }^{\mathrm{c}}$ Mixed infection by TCII and T. rangeli.

${ }^{\mathrm{d}}$ Mixed infection by TCII and TCIII.

e Number of T. cruzi $(n=13)$ and T. rangeli $(n=1)$ isolates/total number of examined bats in all study areas.
}

genotype demonstrates to be widely dispersed in all biomes of the country. The broader dispersion of this taxon certainly has contributed to the previous biased conclusion of an association of $T$. cruzi genotypes to determinate hosts. The high prevalence of infection by T. cruzi II in P. hastatus in the same hollow tree (80\%) shows that this host has competence to amplify this genotype subpopulation of the parasite in the wild. These results support the hypothesis that TCII subpopulations are more difficult to observe in the wild probably because this genotype occurs in more restricted transmission cycles in more delimited and narrower ecological niches. The finding of TCIII/Z3 infected bats enlarges the knowledge concerning dispersion of this subpopulation in the natural environment. In fact, zymodeme 3 (TCIII) is demonstrating to be much more broadly dispersed than formerly believed.

Ours previous and present data do not support an association of $T$. cruzi genotype with any wild mammal species since all three genotypes have already been described infecting Marsupialia, Rodentia, Xenarthra, Carnivora, and Primates in different ecosystem (Lisboa et al., 2006). 


\section{Acknowledgements}

We would like to express our sincere gratitude to Dr. Vera Bongertz for her critical reading and revision of the manuscript. We wish to show thankfulness to Ana Cláudia Machado Duarte, Patrícia Baldino and Mônica Caroline de Oliveira Campos for their technical support in different moments. We thank Dr. Erich Fisher/UFMS for capture of bats specimens in the Pantanal, MS and Vanderson Vaz for capture in Itupiranga, AM. The Financial support has been provided at various times by POM/PAPES - FIOCRUZ, CNPq and Fundação de Apoio ao Desenvolvimento do Ensino, Ciência e Tecnologia do estado de Mato Grosso do Sul (FUNDECT/MS). Lisboa CV is a FAPERJ Visiting Researcher (FIOCRUZ/FAPERJ).

\section{References}

Coura, J.R., Junqueira, A.C.V., Fernandes, O., Valente, S.A.S., Miles, M.A., 2002. Emerging Chagas disease in Amazonian Brazil. Trends Parasitol. 18, 171-176.

Cupolillo, E., Grimaldi Jr., G., Momen, H., 1994. A general classification of New World Leishmania using numerical zymotaxonomy. Am. J. Trop. Med. Hyg. 50, 296-311.

De Freitas, J.M., Augusto-Pinto, L., Pimenta, J.R., Bastos-Rodrigues, L., Gonçalves, V.F., Teixeira, S.M., Chiari, E., Junqueira, A.C., Fernandes, O., Macedo, A.M., Machado, C.R., Pena, S.D., 2006. Ancestral genomes, sex, and the population structure of Trypanosoma cruzi. PLoS Pathog. 2, e24.

Fernandes, O., Santos, S.S., Cupolillo, E., Mendonca, B., Derre, R., Junqueira, A.C., Santos, L.C., Sturm, N.R., Naiff, R.D., Barret, T.V., Campbell, D.A., Coura, J.R., 2001. A mini-exon multiplex polymerase chain reaction to distinguish the major groups of Trypanosoma cruzi and $T$. rangeli in the Brazilian Amazon. Trans. R. Soc. Trop. Med. Hyg. 95, 97-99.
Jansen, A.M., Santos de, A.P., Lisboa, C.V., Cupolillo, E., Mangia, R.H., Fernandes, O., 1999. The sylvatic cycle of Trypanosoma cruzi: a still unsolved puzzle. Mem. Inst. Oswaldo Cruz 94, 203-204.

Lisboa, C.V., Pinho, A.P., Monteiro, R.V., Jansen, A.M., 2006. Trypanosoma cruzi (kinetoplastida Trypanosomatidae): biological heterogeneity in the isolates derived from wild hosts. Exp. Parasitol. 116, 150-155.

Miles, M.A., Lanham, S.M., de Souza, A.A., Povoa, M., 1980. Further enzymic characters of Trypanosoma cruzi and their evaluation for strain identification. Trans. R. Soc. Trop. Med. Hyg. 74, 221-237.

Molyneux, D.H., Stiles, J.K., 1991. Tripanosomatids-vector interactions. Ann. Soc. Belg. Med. Trop. 71, 151-166.

Pavlícek, A., Hrdá, S., Flegr, J., 1999. Free-Tree-freeware program for construction of phylogenetic trees on the basis of distance data and bootstrap/jackknife analysis of the tree robustness. Application in the RAPD analysis of genus Frenkelia. Folia Biol. 45, 97-99.

Rozas, M., De Doncker, S., Adauí, V., Coronado, X., Barnabé, C., Tibyarenc, M., Solari, A., Dujardin, J.C., 2007. Multilocus polymerase chain reaction restriction fragment-length polymorphism genotyping of Trypanosoma cruzi (Chagas disease): taxonomic and clinical applications. J. Infect. Dis. 195, 1381-1388.

Sambrook, J., Fritsch, E.F., Maniatis, T., 1989. Molecular Cloning. A Laboratory Manual. Cold Spring Harbor Laboratory Press, New York.

Satellite Meeting, 1999. Recommendations from a satellite meeting. Mem. Inst. Oswaldo Cruz 94, 429-432.

Stevens, J.R., Noyes, H.A., Dover, G.A., Gibson, W.C., 1999. The ancient and divergent origins of the human pathogenic trypanosomes, Trypanosoma brucei and T. cruzi. Parasitology 118, 107-116.

Tibayrenc, M., Ayala, F.J., 1999. Evolutionary genetics of Trypanosoma and Leishmania. Microbes Infect. 1, 465-472.

Willig, M.R., Camilo, G.R., Nobile, S.J., 1993. Dietary overlap in frugivorous and insectivorous bats from edaphic cerrado habitats of Brazil. J. Mammal. 74, 117-128.

Zortea, M., 2003. Reproductive patterns and feeding habits of three nectarivorous bats (Phyllostomidae: Glossophaginae) from the Brazilian Cerrado. Braz. J. Biol. 63, 159-168. 